\title{
Determination of the particle interactions, rheology and the surface roughness relationship for dental restorative ceramics
}

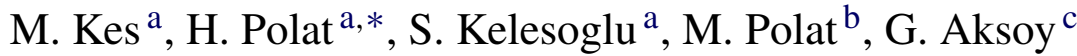 \\ ${ }^{a}$ Department of Chemistry, Izmir Institute of Technology, Urla, Izmir, Turkey \\ ${ }^{\mathrm{b}}$ Department of Chemical Engineering, İzmir Institute of Technology, Urla, İzmir, Turkey \\ ${ }^{\mathrm{c}}$ School of Dentistry, Agean University, Bornova, İzmir, Turkey
}

Received 13 March 2008; received in revised form 7 April 2009; accepted 16 April 2009

Available online 30 May 2009

\begin{abstract}
The effect of inter-particle interactions on the slurry properties and the final surface roughness of the dental ceramic restoratives was investigated. A commercial dental ceramic powder, IPS Empress 2 veneer, was used as the raw material.

The magnitudes of the particle-particle interactions were computed by the DLVO theory for the ceramic slurries of different electrolyte solutions $\left(0.1 \mathrm{M}, 0.25 \mathrm{M}, 0.5 \mathrm{M}, 0.75 \mathrm{M}, 1 \mathrm{M} \mathrm{NaCl}\right.$ and $\mathrm{CaCl}_{2}$ ). As expected, the energies of particle-particle interactions were influenced significantly by the presence of electrolytes. These computations demonstrated that addition of electrolytes leads to a progressive depression of the repulsive double layer forces. The absence of these forces should inevitably lead to agglomeration caused by the ever-present van der Waals forces.

The rheological measurements carried out using the slurries with same solution properties supported the findings of the DLVO computations. It was found that dental ceramic slurries showed a Newtonian behavior in the absence of electrolytes, which is indicative of little or no agglomeration in the slurry. On the other hand, the same slurries displayed a non-Newtonian, shear thinning behavior in the presence of electrolytes which can be attributed to agglomeration or gelation.

Roughness of the ceramic surfaces produced from these slurries was studied by SEM analysis and profilometer measurements. Contact angle studies were also carried out on the same surfaces. It was observed that the surface became rougher initially with electrolyte addition to a maximum, most probably due to formation of isolated agglomerates due to a reduction of the repulsive double layer forces. After reaching a maximum, surface roughness decreased to a much lower value with further increase in electrolyte concentration. This was most probably caused by the formation of a relatively homogeneous, gel-like structure within the extensively agglomerated slurry due to a complete collapse of the double layer.

(C) 2009 Elsevier Ltd. All rights reserved.
\end{abstract}

Keywords: Inter-particle interactions; Rheology; Surface; Dental ceramics; Surfaces; Ceramic; DLVO; Contact angle

\section{Introduction}

Materials which are compatible with body tissues and nontoxic special properties are used to repair or replace diseased, damaged or aged body parts. ${ }^{1}$ Among these, certain metal alloys, ceramics, glasses and glass-ceramics are most suitable for the repair and replacement of hard tissues such as bones whereas inorganics and natural polymeric materials are used for soft tissue replacements as applied in cardiovascular system applications.

\footnotetext{
* Corresponding author. Tel.: +90 232750 7531; fax: +90 2327507509 .

E-mail address: hurriyetpolat@iyte.edu.tr (H. Polat).
}

Depending on their reactivity with the environment, biomedical ceramic materials may be divided into three classes:

(i) biodegradable or resorbable ceramics: calcium phosphates and calcium aluminates,

(ii) relatively bioinert (non-absorbable) ceramics: alumina, zirconia, silicone nitrides, carbons,

(iii) bioactive or surface reactive (semi-inert) ceramics: glass-ceramics, dense hydroxyapatites. ${ }^{2-8}$

Among other applications, relative inertness towards bodily fluids, high compressive strength, and aesthetically pleasant appearance of ceramics have promoted their use as a dental restorative material. ${ }^{9}$ Their ability to yield relatively smooth surfaces is another important reason for their preference in den- 
tal applications since it minimizes plaque deposition and tissue inflammation. However, more importantly, a smooth dental surface is important in reducing wear which is caused by one tooth surface abrading on the opposite due to roughness of their surfaces. This effect is magnified in the case of ceramic restoratives since they are usually harder materials than natural tooth. ${ }^{10}$ Therefore, the degree of surface roughness of dental ceramics is extremely important and its effect on biocompatibility has been widely studied. ${ }^{11-20}$

Microcracks which develop during the firing of these ceramics contribute to surface roughness while decreasing the strength of the restorative material due to stresses accumulating within the crack sites. Both factors significantly reduce the performance of the ceramic restorative materials in oral environment. ${ }^{21-24}$ Development of such cracks may very well be a sign of inconsistencies in the homogeneity, plasticity and forming of the ceramic paste (ceramic green body) in the molding stage. These properties, in turn, depend directly on the type and magnitude of interactions taking place between the particles within the slurry. Despite this obvious link, there is no in-depth study on the relationship between the particle-particle interactions in the dental ceramic slurries and the surface roughness of the fired products.

This study was devised to investigate this link; the effect of particle-particle interactions on the rheological characteristics of ceramic slurries and eventually on the surface roughness of the final dental ceramic products. For this purpose, numerous ceramic slurries were prepared under different electrolytic conditions and subjected to rheological analyses. The magnitudes of the particle-particle interactions for these slurries were computed using the DLVO theory. The surfaces of the final ceramic products from the same slurries were tested using SEM, profilometer and contact angle analyses. The results of these studies were evaluated to ascertain if exists a link between inter-particle interactions and the rheological properties of the dental ceramic slurries; and the effect of such properties on the surface roughness of the final ceramic products.

\section{Materials and methods}

\subsection{Materials}

The all-ceramic system selected for this study was IPS Empress 2 veneer, obtained from Ivoclar Vivadent AG, Schaan, Lichtenstein, which is a sintered glass-ceramic. Composition and some other properties of the powder are given in Tables 1 and 2. A representative SEM picture of the powder is given in Fig. 1.

The average particle size of the powder was obtained as a function of $\mathrm{pH}$ by a Malvern Mastersizer 2000HD and observed to vary as a function of $\mathrm{pH}$ due to agglomeration/dispersion tendency of the particles at different solution chemistry. ${ }^{25,26}$ The particle size at natural $\mathrm{pH}$ (6.86) was $1602 \mathrm{~nm}$ and changed between $500 \mathrm{~nm}$ and $2600 \mathrm{~nm}$ as a function of $\mathrm{pH}$.

The zeta potential of the powder was obtained as a function of $\mathrm{pH}$ by a Malvern Zetasizer Nano ZS and presented in Fig. 2. It can be seen that the powder has a pzc of around pH 3.5 and
Table 1

Properties of the IPS Empress 2 veneer powder. ${ }^{27}$.

\begin{tabular}{|c|c|c|}
\hline \multicolumn{2}{|l|}{ Properties } & \multirow{2}{*}{$\begin{array}{l}\text { Parameters } \\
80 \pm 25 \mathrm{MPa} \\
\text { Similar to that of natural teeth }\end{array}$} \\
\hline Mechanical & $\begin{array}{l}\text { Flexural strength } \\
\text { Abrasion behavior }\end{array}$ & \\
\hline Optical & Translucency & \\
\hline Thermal & $\begin{array}{l}\text { Coefficient of linear } \\
\text { thermal expansion }(\alpha)\end{array}$ & $9.7 \pm 0.5 \times 10^{-6} \mathrm{~K}^{-1} \mathrm{~m} / \mathrm{m}$ \\
\hline Chemical & Solubility & $<100 \mu \mathrm{g} / \mathrm{cm}^{2}$ \\
\hline Technical & Sintering temperature & $800^{\circ} \mathrm{C}$ \\
\hline
\end{tabular}

Table 2

Composition of the IPS Empress 2 veneer powder. ${ }^{27}$.

\begin{tabular}{ll}
\hline Components & wt $\%$ \\
\hline $\mathrm{SiO}_{2}$ & $45-70$ \\
$\mathrm{Al}_{2} \mathrm{O}_{3}$ & $5-22$ \\
$\mathrm{P}_{2} \mathrm{O}_{5}$ & $0.5-6.5$ \\
$\mathrm{~K}_{2} \mathrm{O}$ & $3-9$ \\
$\mathrm{Na}_{2} \mathrm{O}$ & $4-13$ \\
$\mathrm{CaO}$ & $1-11$ \\
$\mathrm{~F}$ & $0.1-2.5$
\end{tabular}

Additional components: $\mathrm{B}_{2} \mathrm{O}_{3}, \mathrm{La}_{2} \mathrm{O}_{3}, \mathrm{Li}_{2} \mathrm{O}, \mathrm{BaO}, \mathrm{MgO}$, $\mathrm{ZnO}, \mathrm{SrO}, \mathrm{TiO}_{2}, \mathrm{ZrO}_{2}, \mathrm{CeO}_{2}$, approx. $10 \mathrm{wt} \%$

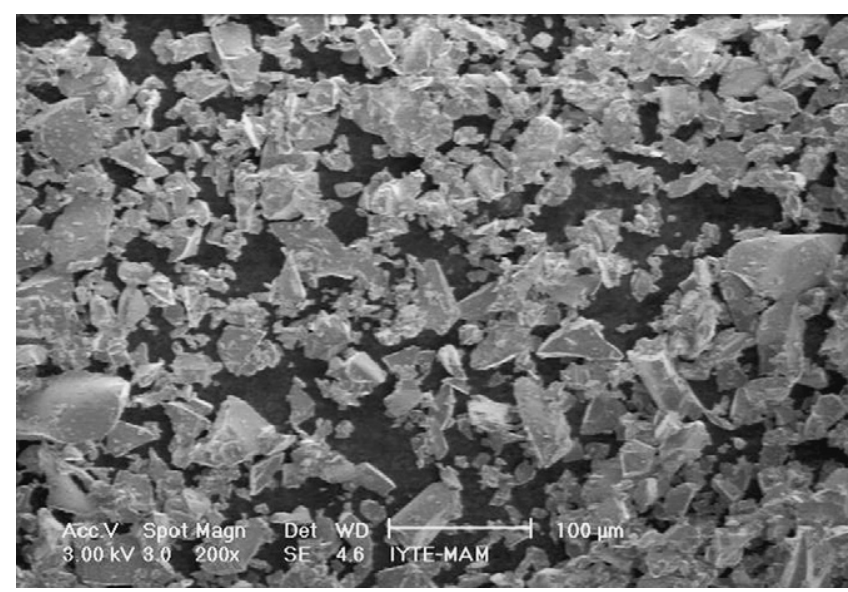

Fig. 1. SEM picture of IPS Empress 2 veneer powder $(100 \times)$.

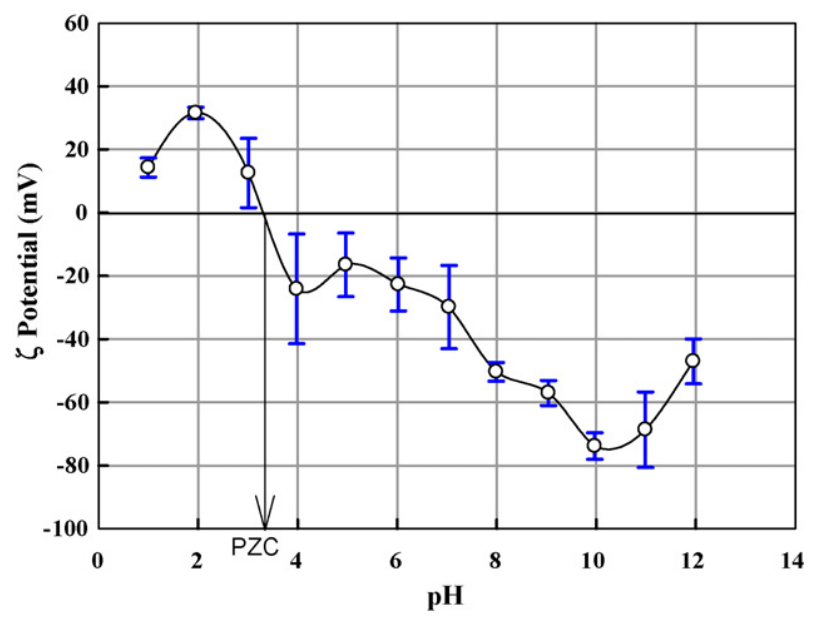

Fig. 2. Zeta potential graph of IPS Empress 2 veneer powder. 
is predominantly negatively charged in the natural $\mathrm{pH}(6.86)$ of the slurry.

The distilled water used in preparing the ceramic pastes was through a Barnstead Easypure UV-Compact ultrapure water system and had a resistance of $18.3 \Omega$. The electrolyte solutions were prepared from this water using analytical grade $\mathrm{NaCl}$ and $\mathrm{CaCl}_{2}$ obtained from Sigma.

\subsection{Methods}

\subsubsection{Preparation of dental ceramic samples}

Four disc-shaped specimens $(d=10 \mathrm{~mm}, h=5 \mathrm{~mm})$ of IPS Empress 2 veneering porcelain were fabricated by mixing the powder with $\mathrm{NaCl}$ and $\mathrm{CaCl}_{2}$ electrolyte solutions of varying strengths $(0.1 \mathrm{M}, 0.25 \mathrm{M}, 0.5 \mathrm{M}, 0.75 \mathrm{M}$, and $1 \mathrm{M})$ on a glass Petridish with a spatula until porcelain paste was formed. The $\mathrm{pH}$ of the paste was measured to be 10 without any adjustments. The porcelain slurry was then filled into a plastic cylindrical mould with 10-mm internal diameter and 5-mm height. The excess liquid was blotted from the slurry with an absorbent paper. After forming, the porcelain pastes in green body form were removed from the mould and placed on a refractory tray for firing. All specimens were fired in a programmable and calibrated porcelain furnace (Programat P90, Ivoclar-Vivadent, Schaan, Liechtenstein) with the firing cycle set for a 6-min climb to at $60^{\circ} \mathrm{C} / \mathrm{min}$ increments with 2 -min holding time at $840^{\circ} \mathrm{C}$. A vacuum was initiated when the temperature reached at $450{ }^{\circ} \mathrm{C}$. It was sustained until the end of the 2 min hold at $840^{\circ} \mathrm{C}$. After 2 min, vacuum was turned off and the samples were kept in the furnace until cooling to room temperature. ${ }^{28}$ The cintered samples were cleaned by ultrasonic treatment for $10 \mathrm{~min}$ (Ceia CP 102 Ultrasonic Cleaner, Italy) and used for surface analyses without any other surface treatment.

\subsubsection{Rheology measurements}

A Brookfield DV III+ rheometer with an ULA adapter was used to investigate the rheological behavior of the IPS Empress 2 porcelain slurry at $60 \%(\mathrm{w} / \mathrm{v})$ ratio which had a natural $\mathrm{pH}$ of 10 . The shear stresses and viscosities of this slurry were measured as a function of shear rate using the following set conditions:

- Speed was set at minimum value of $10 \mathrm{rpm}$.

- It was increased to $100 \mathrm{rpm}$ by $10 \mathrm{rpm}$ intervals in every $10 \mathrm{~s}$.

The shear rate range was varied between $0 \mathrm{~s}^{-1}$ to $140 \mathrm{~s}^{-1}$.

\subsubsection{Profilometry}

The roughness of the fired porcelain discs was measured with a stylus profilometer (Mitutoyo Surftest SJ-201P, Japan) which could provide surface roughness scans with $0.01 \mu \mathrm{m}$ resolution between $0.01 \mu \mathrm{m}$ and $100 \mu \mathrm{m}$ using a $2 \mu \mathrm{m}$-diameter diamond stylus. The average surface roughness value, $R_{\mathrm{a}}$, was determined on a $0.8 \mathrm{~mm}$ sampling length using three repeat scans. For each porcelain disc at least 10 measurements were done. The $R_{\mathrm{a}}$ value is the arithmetic average of the height of peaks and depth of valleys from a mean line expressed in nanometers.

\subsubsection{Scanning electron microscopy (SEM)}

The SEM (Philips XL 30SFG) was utilized to obtain representative pictures of the profilometer-scanned surfaces at $2500 \times$ magnification. However, the SEM results are included only for illustration purposes since the locations of the profilometer and SEM scans may vary.

\subsubsection{Contact angle measurements}

Contact angles were measured using sessile drops on the fired ceramic surfaces immersed in air with a goniometer/microscope setup (Krüss GmbH, Germany model G10). The method employed is a modified one suggested by Polat and Chander $^{29}$ and allows observation of a distribution of contact angles on a given surface. In this method, the ceramic surface was divided into a $4 \times 4$ grid for contact angle measurement and a micro-droplet of double-distilled water $(\sim 5 \mu \mathrm{l})$ generated with a micrometer syringe was placed on a selected portion of the grid using a micro-positioning device and a micrometer-driven micropipette. The angle which developed at the three point air/water/ceramic contact was measured using the microscope-goniometer system. The process was repeated for each grid point to yield at least 16 measurements for each sample.

\section{Results and discussion}

\subsection{Particle-particle interactions}

The interaction between particles of colloidal powders in solution is traditionally described by the DLVO theory. ${ }^{25,26,30-33}$ This theory states that, in the absence of any other components such as surfactants or polymers, the net energy of interaction between two surfaces dispersed in an electrolyte solution is a sum of electrical double layer and van der Waals forces.

van der Waals forces arise from the interactions of permanent, induced or instantaneous dipoles between the atoms or molecules of any matter. Though the theory behind this interaction is vast, the energy of van der Waals interaction between two particles of diameters $d_{1}$ and $d_{2}$ can be conveniently given by the equation:

$V_{v d W}=-\frac{A_{132} d_{1} d_{2}}{12\left(d_{1}+d_{2}\right) h}$

Here, $h$ is the gap separating the particles. The term $A_{132}$ is called the Hamaker constant and represents the effective Hamaker constant for particles 1 and 2 interacting through medium 3 . For the silica-water-silica system used in our experiments, the effective Hamaker constant $A_{s w s}$ is estimated to be $3.83 \times 10^{-20} \mathrm{~J}^{32}$

An ionic environment spontaneously develops around a solid when it is immersed in a liquid due to different chemical activities of ions in solid and liquid phases. Accumulation of charge on the solution side requires a finite thickness because of an interplay between electrostatic interactions and the thermal disturbance, which is properly dubbed as the diffuse layer. These two charged regions (the solid and the diffuse layer; see Fig. 3) are called the Electrical Double Layer (EDL). 


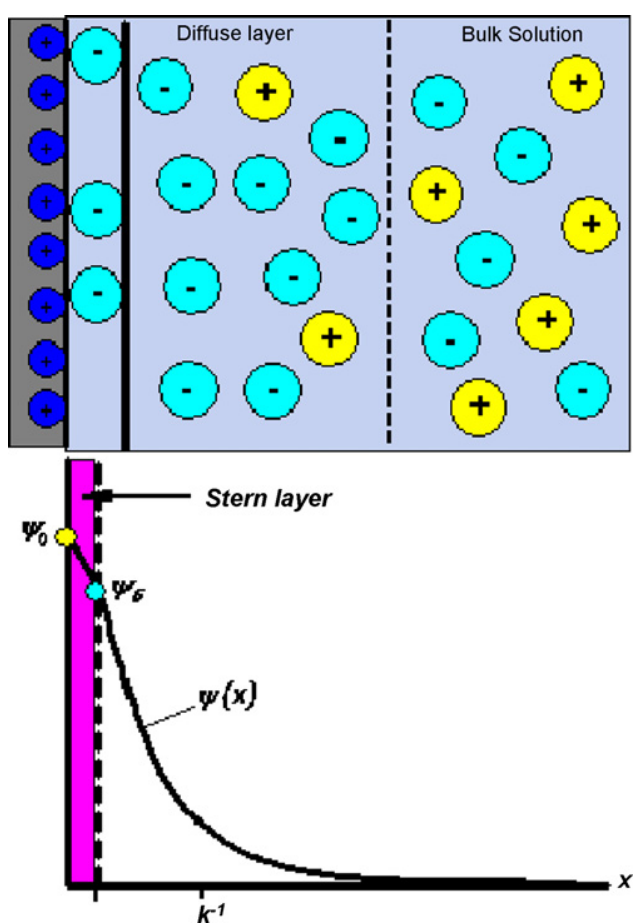

Fig. 3. Development of a diffuse layer of charge in response to spontaneous charging of a solid in liquid (the electrical double layer, EDL) and the change of potential $\psi(x)$ in the EDL as a function of distance $x$ from the solid surface.

There is a potential difference between the solid surface and any point $x$ in the diffuse layer which leads to an exponentially decreasing potential profile $\psi(x)$ in the EDL (Fig. 3). The shape of this potential profile depends on such factors as the magnitude of surface charge, electrolyte concentration in solution, etc. An interaction of the potential profiles (interaction of the electric fields of respective diffuse layers) occurs when two solid surfaces come into vicinity of each other. This interaction leads to an electrostatic repulsion which is extremely important in controlling and manipulating colloidal behavior. The magnitude of this interaction is directly related to the magnitude of the diffuse layer potential profiles of the two solids.

The differential equation which quantitatively defines how $\psi(x)$ varies with $x$ is called the Poisson-Boltzmann (PB) equation:

$\frac{d^{2} \psi(x)}{d x^{2}}=\frac{\kappa^{2} R T}{z F} \sinh \left[\frac{z F \psi(x)}{R T}\right]$

Here, $R$ is the gas constant, $T$ is the temperature, $z$ is the valence of the electrolyte, $F$ is the Faraday's constant. The term $\kappa$ is a collection of terms and is related to the thickness of the diffuse layer.

A popular solution of the PB equation for 1:1 electrolyte systems is called the Gouy-Chapman model of the EDL. According to this model, the potential changes in the diffuse layer according to the following equation. ${ }^{31}$

$\frac{\tanh [z F \varphi(x) / 4 R T]}{\tanh \left[z F \varphi_{0} / 4 R T\right]}=e^{-\kappa x}$
Here, $\psi_{0}$ is the potential on the solid's surface (at $x=0$ ). Based on this solution, $\kappa$ comes out to be equal to:

$\kappa=\sqrt{\frac{2 z^{2} F^{2} C_{0}}{R T \varepsilon \varepsilon_{0}}}$

Here, $C_{0}$ is the electrolyte concentration of the solution whereas $\varepsilon_{0}$ and $\varepsilon$ are the dielectric constants of the vacuum and water, respectively.

When two surfaces are in close vicinity in solution (a distance $h$ apart), the diffuse layer on one surface starts feeling the presence of the other's, which means their potential fields begin to interact. This mutual interaction results in an electrostatic pressure. It follows that the interaction of surfaces will take place at longer distances when the relative thicknesses of the diffuse layers are large. Then, one should expect that surfaces will resist coming into closer approach due to interaction of their respective diffuse layers at low electrolyte concentrations which lead to a much thicker EDLs.

Though various analytical and numerical solutions exist, one can quantitatively calculate the electrostatic interaction energy for two particles of diameters $d_{1}$ and $d_{2}$ with moderate surface potentials using: ${ }^{32-35}$

$$
\begin{aligned}
V_{e l}= & \frac{\pi \varepsilon \varepsilon_{0} d_{1} d_{2}}{2\left(d_{1}+d_{2}\right)}\left[2 \psi_{01} \psi_{02} \ln \left(\frac{1+e^{-\kappa H}}{1-e^{-\kappa H}}\right)\right. \\
& \left.+\left(\psi_{01}^{2}+\psi_{02}^{2}\right) \ln \left(1-e^{-2 \kappa h}\right)\right]
\end{aligned}
$$

The terms $\psi_{01}$ and $\psi_{02}$ are the surface potentials on particles 1 and 2 interacting through the gap $h$.

The total energy of interaction for two particles in close approach will be a sum of van der Waals and electrostatic interactions. Hence, a summation of Eqs. (1) and (5) gives the total interaction energy $\left(V_{t o t}=V_{v d w}+V_{e l}\right)$. However, it should be noted that the van der Waals component is mainly affected by the bulk properties of the interacting bodies and the separating medium. Since the bulk properties of both the dental ceramic powder and the separating water remain essentially unchanged, the changes in the van der Waals component of the interaction will be minimal with changes in such solution properties as electrolyte concentration and can be neglected. The electrostatic force, on the other hand, is strongly influenced by the solution chemistry. Therefore, it is usually the component of interest to influence the stability and rheological behavior of the colloidal systems.

\subsection{Interaction energy curves for the IPS Empress 2 veneer powder}

The changes in the potential profile $\psi(x)$ of the IPS Empress 2 veneer powder in $\mathrm{NaCl}$ and $\mathrm{CaCl}_{2}$ solutions were plotted in Fig. 4 using Eq. (3). The electrolyte concentrations, $C_{0}$, used in plotting the graphs were $0.001 \mathrm{M}, 0.1 \mathrm{M}, 0.25 \mathrm{M}, 0.5 \mathrm{M}, 0.75 \mathrm{M}$ and $1 \mathrm{M}$. Though the distilled water used would actually correspond to a much more dilute system, the electrolyte concentration of $0.001 \mathrm{M}$ in this figure was selected to show the effect of a dilute 


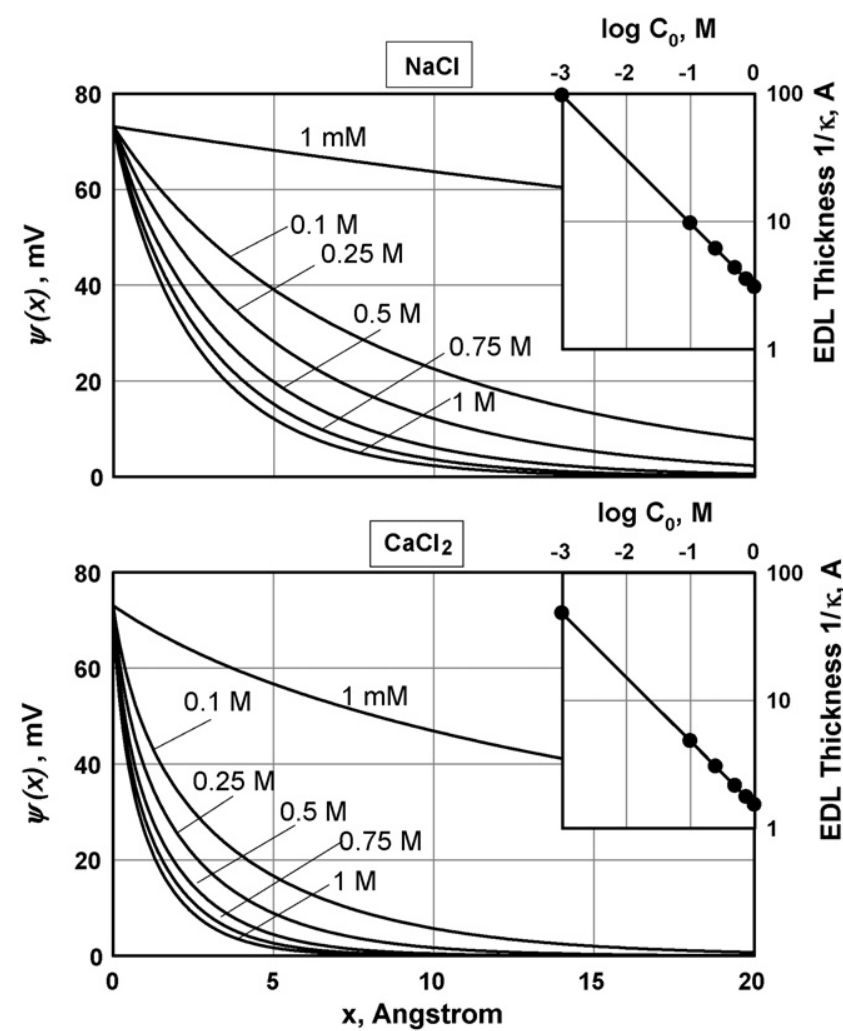

Fig. 4. Potential profile of IPS Empress 2 veneer powder in $\mathrm{NaCl}$ and $\mathrm{CaCl}_{2}$ solutions at different concentrations $\left(\mathrm{pH} \mathrm{10,} \psi_{0}=-73.1 \mathrm{mV}\right)$.

electrolyte for illustrative purposes. The surface (zeta) potential $\psi_{0}$ of the powder was $73.1 \mathrm{mV}$ at $\mathrm{pH} 10$ (see Fig. 2, the zeta potential curve). ${ }^{34}$ The reason for selecting this $\mathrm{pH}$ value was because it was the natural $\mathrm{pH}$ of the ceramic slurry at high solid loadings used in this work.

As the figure demonstrates, the potential profiles, hence the diffuse layer, become more compact both with increasing electrolyte concentrations and electrolyte valence. This means that the thickness of the ionic atmosphere around the particles decreases significantly under these conditions. For example, while the effective thickness of EDL ( $1 / \kappa$ value) was $96 \AA$ for the very dilute $\mathrm{NaCl}$ concentration of $1 \mathrm{mM}$, it decreased to less than $10 \AA$ for $\mathrm{NaCl}$ concentrations of $0.1 \mathrm{M}$ and higher. Hence, while one should expect significant electrostatic repulsion between particles few hundred Angstrom apart at low electrolyte strengths (where the diffuse layers of each particle extends deep into solution) the particle would approach to much closer distances at high electrolyte concentrations (where the attractive van de Waals forces are predominant).

The potential energy curves using Eqs. (1) and (5) were computed using the same conditions employed in Fig. 4. The results are presented in Fig. 5. It can be seen that the potentials energy curves show an energy barrier (the energy hill towards positive side observed in each curve) whose magnitude decreases with increasing electrolyte concentration. This barrier can be visualized as the resistance experienced by the particles as they try to come into closer approach. For example, the maximum magnitude of the energy barrier is around $490 \mathrm{kT}$
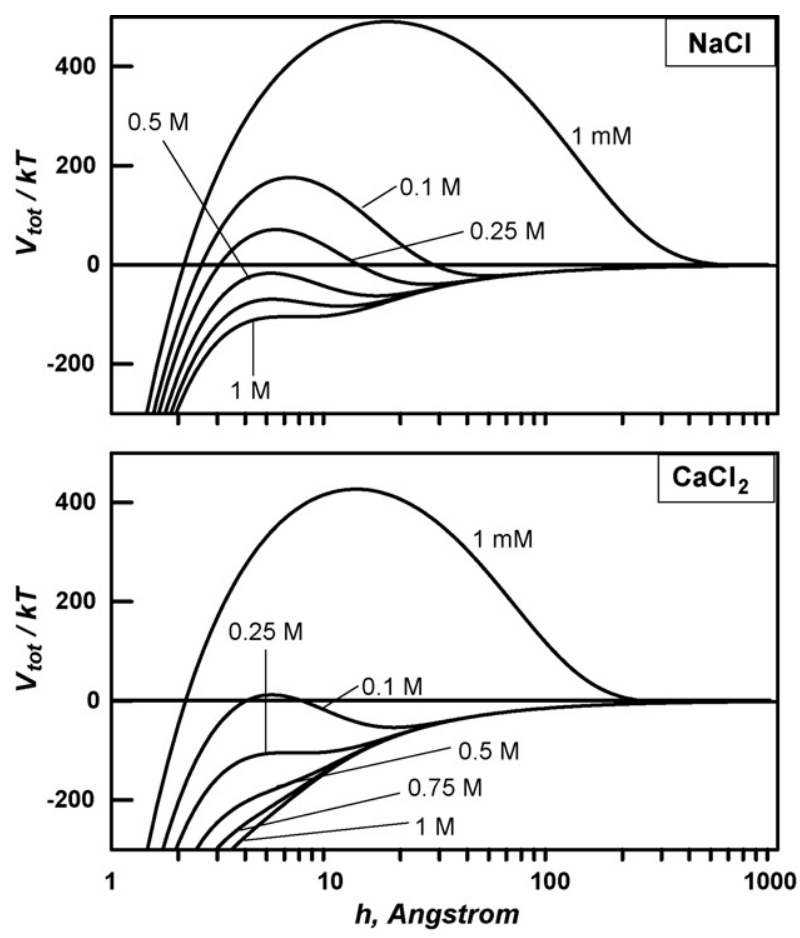

Fig. 5. Potential energy curves of IPS Empress 2 veneer powder as a function of $\mathrm{NaCl}$ and $\mathrm{CaCl}_{2}$ concentrations $\left(d_{1}=d_{2}=350 \mathrm{~nm}, \mathrm{pH} 10, \psi_{0}=-73.1 \mathrm{mV}\right.$, $A_{s w s}=3.83 \times 10^{-20} \mathrm{~J}, T=25^{\circ} \mathrm{C}$ ).
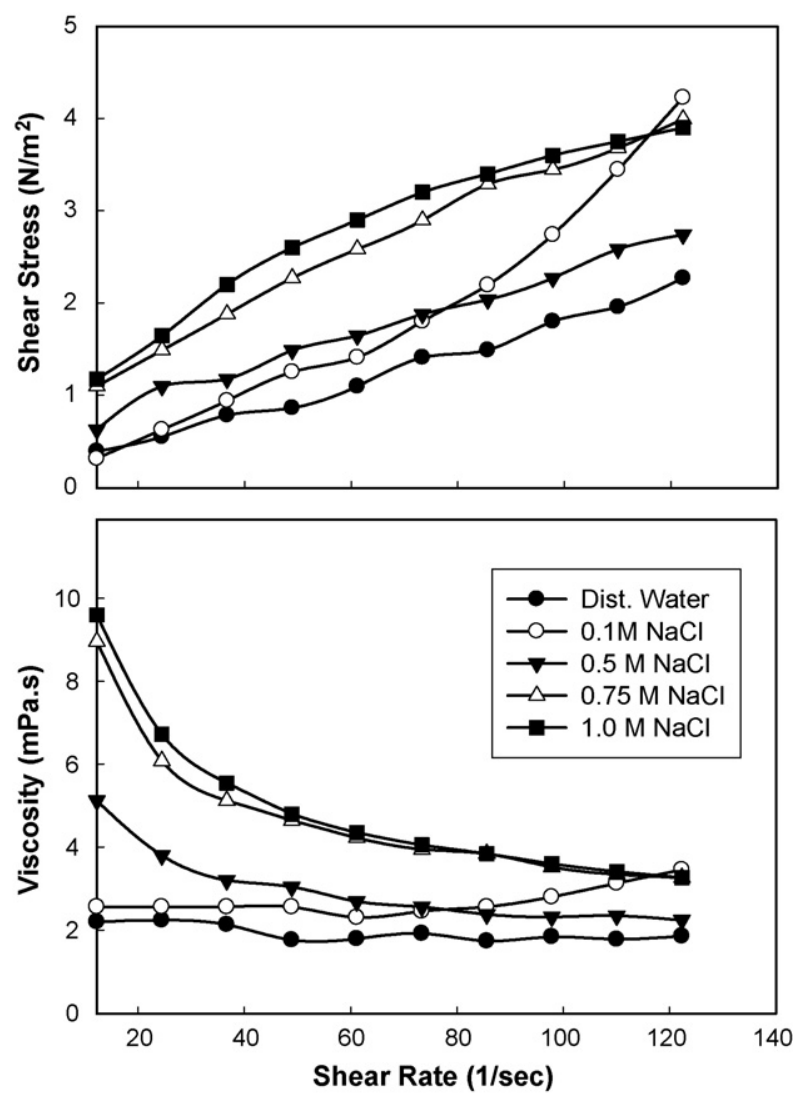

Fig. 6. Rheological behavior of IPS Empress 2 veneer ceramic powder in $\mathrm{NaCl}$ solutions. 

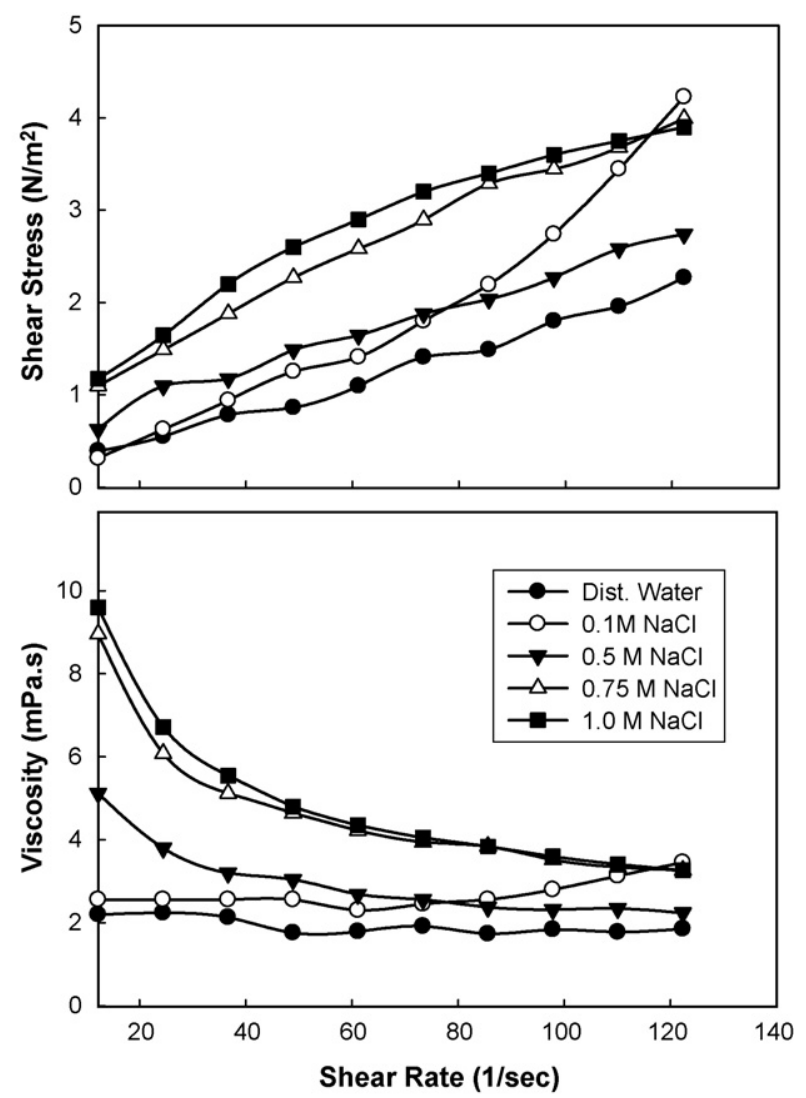

Fig. 7. Rheological behavior of IPS Empress 2 veneer ceramic powder in $\mathrm{CaCl}_{2}$ solutions.

(around $201 \times 10^{-20} \mathrm{~J}$ ) when the $\mathrm{NaCl}$ concentration is $0.001 \mathrm{M}$, but decreases to around $71 \mathrm{kT}$ (around $29 \times 10^{-20} \mathrm{~J}$ ) when the $\mathrm{NaCl}$ concentration reaches $0.250 \mathrm{M}$. There is no energy barrier for $0.5 \mathrm{M}, 075 \mathrm{M}$ and $1 \mathrm{M} \mathrm{NaCl}$ concentrations. A similar observation can also be made for the $\mathrm{CaCl}_{2}$ where there is a positive energy barrier only for $0.001 \mathrm{M}$ and $0.1 \mathrm{M} \mathrm{CaCl}_{2}$ concentrations.

These calculations show that in the absence of any electrolytes, there is an energy barrier between the ceramic particles which oppose to their agglomeration due to the repulsive electrostatic interactions between particles because of a significant surface charge (zeta potential $=-73.1 \mathrm{mV}$ ) at $\mathrm{H} 10$. This will simply mean a well-dispersed system under these conditions. In the presence of a high amounts of electrolyte, however, particles will tend to come much closer due to compression of the double layer (as is apparent from the $1 / \kappa$ values in Fig. 4) and will be under the influence of the attractive van der Waals forces. This would cause a decrease in the magnitude of the energy barrier and favor agglomeration. Agglomeration tendency of the slurry should increase with electrolyte concentration.

The change from a well-dispersed state to an agglomerated state should have observable changes on the slurry properties of the ceramic slurries, probably on the surface roughness of the final ceramic products. Therefore, the rest of the study given in the following sections was designed to observe if this was actually the case.
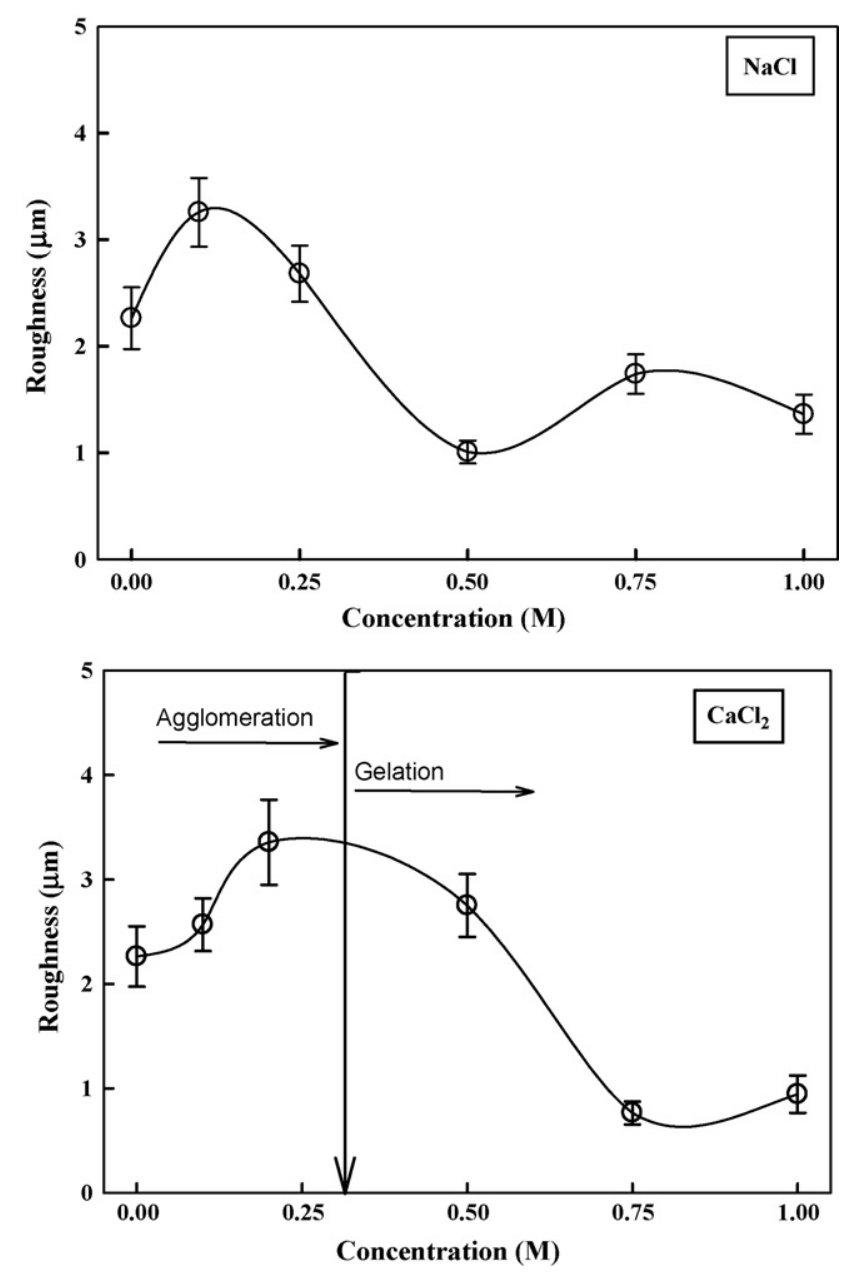

Fig. 8. Roughness of IPS Empress 2 veneer ceramic surfaces prepared with distilled water, $\mathrm{NaCl}$ and $\mathrm{CaCl}_{2}$ solutions.

\subsection{Rheology measurements}

Rheology measurement was carried out to understand the effect of particle interactions on the flow characteristics of the ceramic pastes using solutions of $\mathrm{NaCl}$ and $\mathrm{CaCl}_{2}$ at different concentrations (including distilled water). The solution $\mathrm{pH}$ used was the natural $\mathrm{pH}$ of the slurry $(\sim \mathrm{pH} 10)$ at the solid percentage used $(60 \%$ by w/v). As it is seen from Figs. 6 and 7 that the slurry prepared using distilled water showed Newtonian behavior. The change of shear stress as a function of shear rate was linear and the change of viscosity as a function of shear rate was constant as in the case of Newtonian systems. This shows that there is no flocculation of particles in the absence of any ions in the system. Progressive addition of $\mathrm{NaCl}$ brings the system slightly shear thickening behavior at the lowest concentration. The slight increase of viscosity as a function of shear rate is an indication of this behavior. However, further electrolyte addition changed the behavior from shear thickening to shear thinning (pseudoplastic). This kind of rheological behavior (the decrease observed in the viscosity with increasing shear rate) is known to take place in flocculated systems. This effect becomes more apparent with an increase in electrolyte con- 

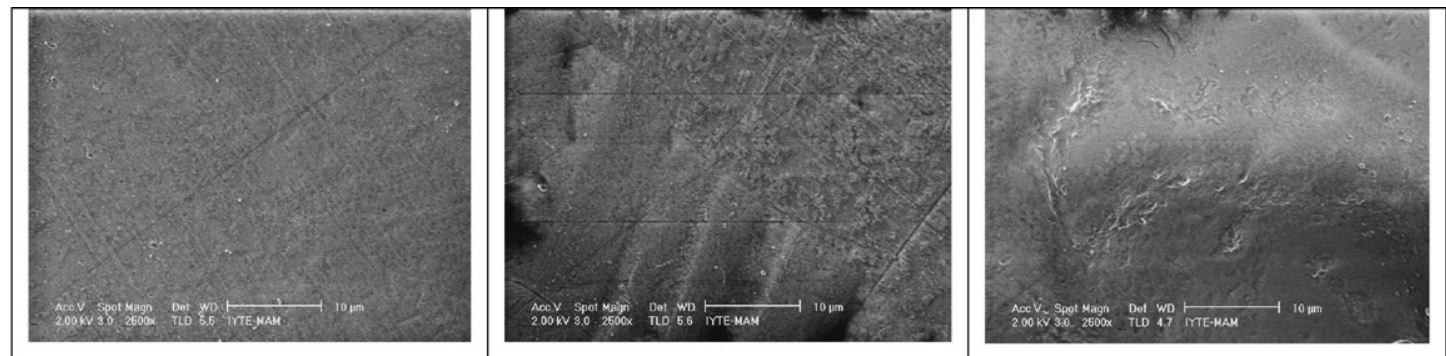

\section{Distilled water}

$0.1 \mathrm{NaCl}$

\section{$0.25 \mathrm{M} \mathrm{NaCl}$}
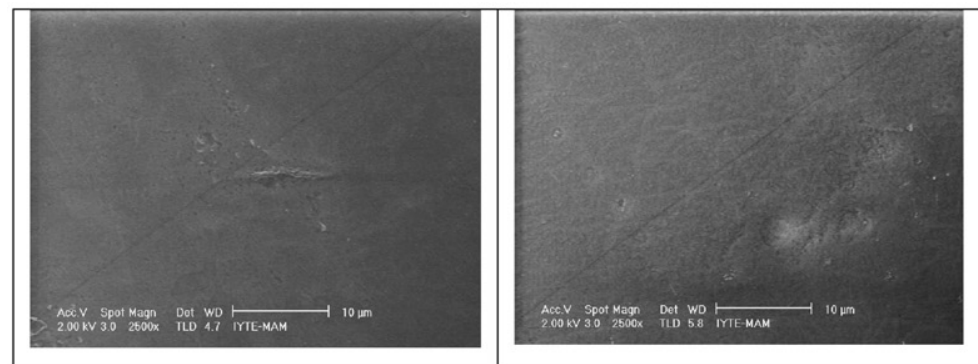

$0.5 \mathrm{M} \mathrm{NaCl}$

$0.75 \mathrm{M} \mathrm{NaCl}$

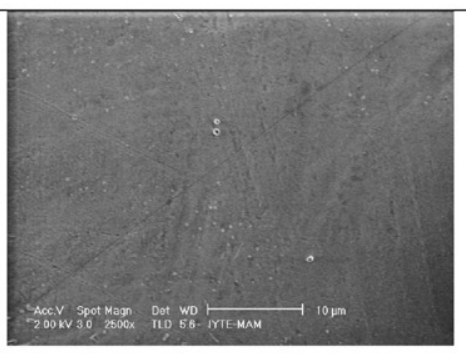

$1.0 \mathrm{M} \mathrm{NaCl}$
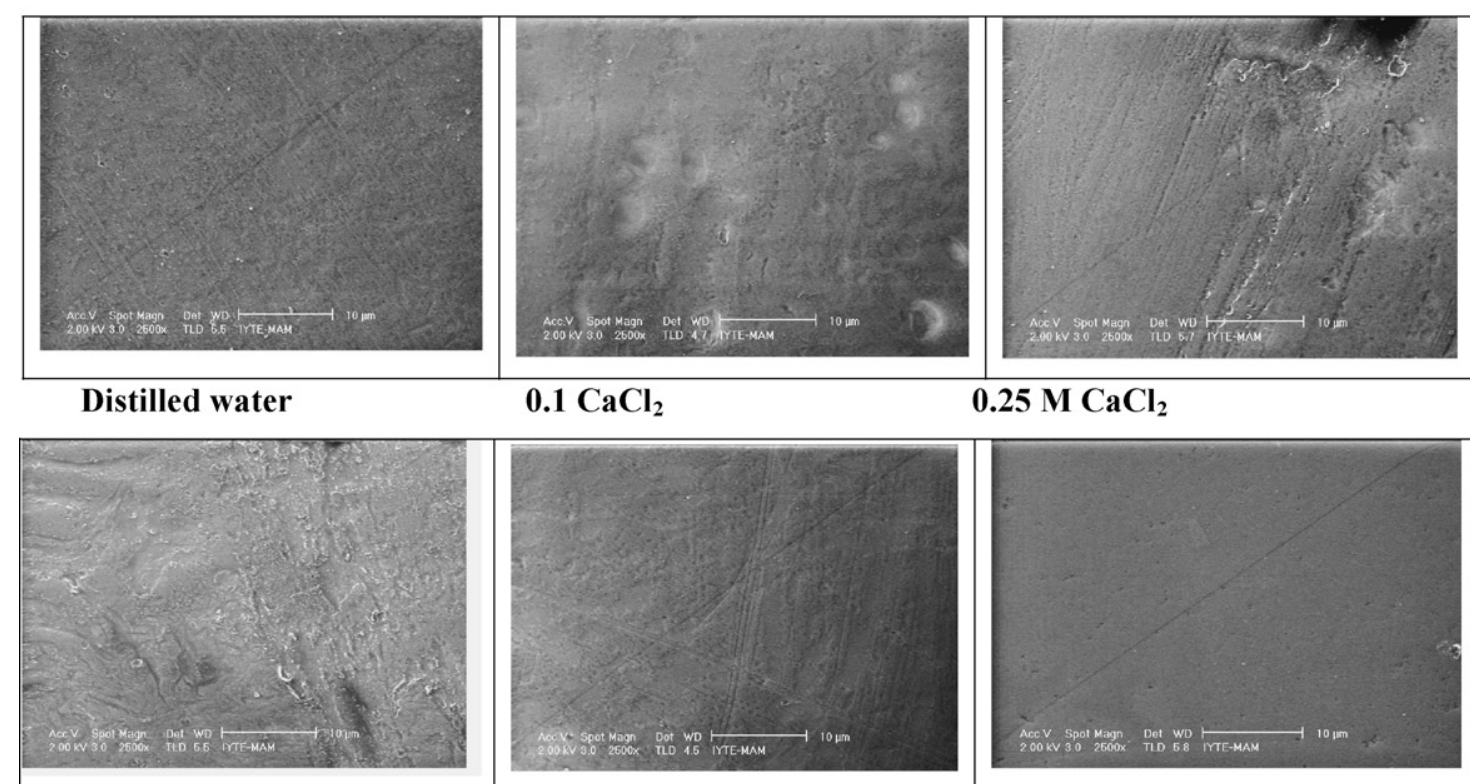

$0.1 \mathrm{CaCl}_{2}$

$0.25 \mathrm{M} \mathrm{CaCl}_{2}$

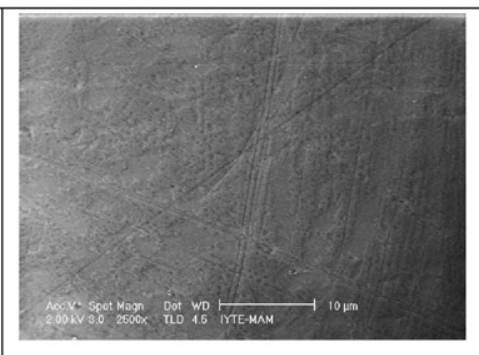

$0.75 \mathrm{M} \mathrm{CaCl}_{2}$

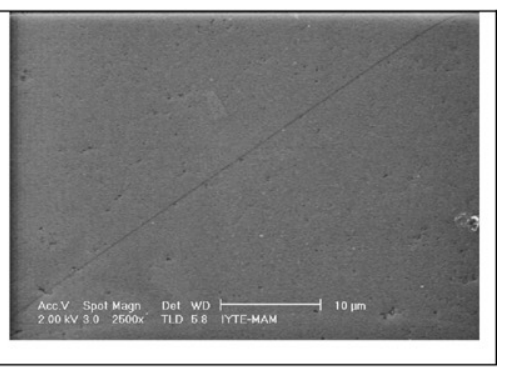

1.0 $\mathrm{M} \mathrm{CaCl}_{2}$

Fig. 9. SEM images of IPS Empress 2 veneer ceramic surfaces prepared with distilled water, $\mathrm{NaCl}$ and $\mathrm{CaCl}_{2}$ solutions.

centration. In the case of $\mathrm{CaCl}_{2}$, there is no shear thickening behavior at the lowest concentration studied. The behavior was always shear thinning for all the concentrations studied. It is also known that most ceramic suspensions show shear thinning behavior. ${ }^{39}$

Gelation of the slurry is also known to be responsible for producing the shear-thinning behavior. When gelation exist, particles are constantly subjected to forces which pull them in and cause them to join the forming gel structures. When gel structures are sheared, the greater the imposed shear rate, the more gel structure is broken, and generally, the lower will be the suspension's measured viscosities. The limiting (minimum) viscosity in shear-thinning fluids occur when gel structures have been totally disrupted and all particles travel as individuals. When shear stresses are reduced, gel structures will reform and suspension viscosity will become higher. When shear stresses are removed, shear flow will stop and gelation will cause the complete structure reform.

As a result of this study, it was seen that particles not only come together to form agglomerates with electrolyte addition, but they also seem to form gel-like structure at very high electrolyte concentrations. This gel-like behavior structure can be visualized as a homogeneous, all-encompassing uniform agglomerated structure. 


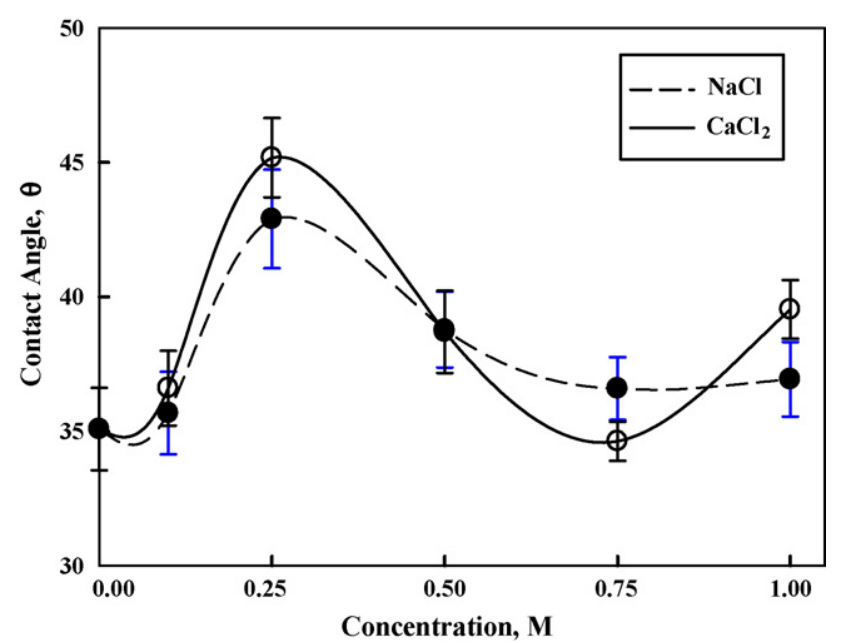

Fig. 10. Contact angle of IPS Empress 2 veneer ceramic surfaces prepared with distilled water, $\mathrm{NaCl}$ and $\mathrm{CaCl}_{2}$ solutions.

\subsection{Surface roughness analyses}

\subsubsection{Profilometer measurements}

$R_{\mathrm{a}}$ values (average surface roughness) obtained from profilometer readings on the fired ceramic surfaces are given as a function of $\mathrm{NaCl}$ and $\mathrm{CaCl}_{2}$ concentrations $(0 \mathrm{M}, 0.1 \mathrm{M}, 0.25 \mathrm{M}$, $0.5 \mathrm{M}, 0.75 \mathrm{M}, 1.0 \mathrm{M})$ in Fig. 8. The roughness of original surface without any added electrolytes (in case of distilled water) was found to be $2.3 \mu \mathrm{m}$. This was marked as zero electrolyte concentration in the figures. In case of $\mathrm{NaCl}$, an initial electrolyte addition $(0.1 \mathrm{M})$ increased the surface roughness up to $3.3 \mu \mathrm{m}$ then decreased down to $1 \mu \mathrm{m}$ in case of $0.5 \mathrm{M}$ of $\mathrm{NaCl}$. $\mathrm{CaCl}_{2}$ also showed a similar trend. There was an increase first at $0.25 \mathrm{M}$ up to $3.3 \mu \mathrm{m}$ followed by a reduction in roughness down to $0.75 \mu \mathrm{m}$ at $0.75 \mathrm{M}$. In both cases, after these concentrations, where the lowest roughness values were obtained, the $R_{\mathrm{a}}$ values become slightly larger with further increase in concentration. However this increase did not seem to be significant.

\subsubsection{Scanning electron microscope (SEM) analyses}

Representative SEM images were collected randomly at 2500 magnification to have an idea about the appearance of the fired ceramic surfaces. These SEM images are in good agreement with the profilometer results. That is, there are enough changes in the surface roughness which are visible to the eye at these magnifications as a function of electrolyte concentration (Fig. 9).

\subsubsection{Contact angle measurements}

The micro-contact angles measured on the surfaces are presented in Fig. 10. The symbols in the figure give the mean contact angles for 60 readings along with the error bars for two-standard deviation spread around this mean. It is immediately clear that the contact angle values follow almost the same trend observed from the results of the surface roughness measurements as a function of electrolyte concentration (see Fig. 8).

The mean contact angle values were $33^{\circ}$ in the absence of any electrolyte in the system. This value increased to $42^{\circ}$ and $45^{\circ}$ with the initial addition of $\mathrm{NaCl}$ and $\mathrm{CaCl}_{2}$, respectively, then was reduced to $35^{\circ}$ with further increase in electrolyte concentration. This simply means that the roughest surface displayed the highest contact angle. This is in agreement with the findings of other literature on the effect of surface roughness on contact angle values. ${ }^{24,34,36-38}$

\subsection{Conclusions}

The magnitudes of particle-particle interactions were computed for dental ceramic slurries as a function of electrolyte type and strength using the DLVO theory to ascertain the effect of these interactions on the rheological behavior. As the next step, the surface roughness of the fired ceramic surfaces manufactured from the same slurries were measured using such techniques as profilometer, SEM and contact angle measurements.

The magnitude of the particle-particle interactions were found to be strongly influenced by the electrolyte concentration of the slurry. The computations of particle-particle interactions carried out at electrolyte strengths of $0.001 \mathrm{M}, 0.1 \mathrm{M}, 0.25 \mathrm{M}$, $0.5 \mathrm{M}, 0.75,1 \mathrm{M}$ for monovalent $(\mathrm{NaCl})$ and bivalent $\left(\mathrm{CaCl}_{2}\right)$ electrolytes clearly showed that repulsive interactions between particles can be significant at low electrolyte concentrations, providing dispersion of the particles in the slurry. Conversely, there was no discernable repulsion between the particles at high electrolyte concentrations. Under these conditions interactions should lead to agglomeration due to the presence of attractive van der Waals forces.

The macroscopic implications of these interactions were investigated by rheological measurements carried out with the same slurry compositions employed in the particle-particle interaction computations. It was found that dental ceramic slurries showed Newtonian behavior in the absence of electrolytes where a well-defined energy barrier, hence a well-dispersed slurry, was predicted. This finding is in agreement with the ceramic literature where dispersed slurries were reported to show a clear Newtonian behavior. ${ }^{39}$ On the other hand, a nonNewtonian behavior was observed in the presence of electrolytes where particle-particle interaction computations predict small or no barrier against agglomeration. Again, it is well known that agglomerated slurries often demonstrate a non-Newtonian behavior. The non-Newtonian behavior observed for our slurries was observed to be shear thinning-gelation type.

The analysis of the surfaces of the fired ceramics from the same slurries using SEM, profilometer and contact angle measurements showed an initial increase in the surface roughness with electrolyte addition. However, after a critical electrolyte concentration, the surface roughness decreased to a lower value and remained relatively constant with a further increase in concentration. The initial increase in surface roughness was attributed to the presence of electrolyte promoting well-defined, isolated agglomerates which tend to create microscopic defects in the ceramic paste and lead to surface defects. The decrease in surface roughness with further increase in electrolyte concentration was attributed to gelation and homogenization of the extensively agglomerated slurry due to a complete collapse of the repulsive electrical double layer. 


\section{Acknowledgment}

The authors gratefully acknowledge Izmir Institute of Technology for financial support to the project (Project no: 2006 IYTE 14).

\section{References}

1. Callister, W. D., Fundamentals of Materials Science and Engineering. Wiley, New York, 2001

2. Hench, L. L., Biomaterials. Science, 1980, 208, 826-831.

3. Hench, L. L., Bioceramics: from concept to clinic. J. Am. Ceram. Soc., 1991, 74, 1487-1510.

4. Hench, L. L., Bioceramics: from concept to clinic. Am. Ceram. Soc. Bull., 1993, 74, 93-98.

5. Hentrich, R. L., Graves, G. A., Stein, H. G. and Bajpai, P. K., An evaluation of inert and resorbable ceramics for future clinical applications. J. Biomed. Mater. Res., 1971, 5, 25-51.

6. Graves Jr., G. A., Hentrich R.L.Jr., Stein, H. G. and Bajpai, P. K., In Resorbable Ceramic Implants in Bioceramics. Engineering and Medicine, Part I, ed. C. W. Hall, S. F. Hullbert, S. N. Levine and F. A. Young. Wiley, New York, 1972, pp. 91-115.

7. Park, J. B. and Lakes, R. S., Biomaterials: An Introduction. Springer-Plenum Press, New York, 1992, p. 3-29.

8. Bhat, S. V., Biomaterials. Kluwer Academic Publishers, Dordrecht, 2002, p. 39.

9. Park, J. B. and Bronzino, J. D., Biomaterials, Principles and Applications. CRC Press, Florida, 2003, p. 21.

10. Kawai, K. and Urano, M., Adherence of plaque components to different restorative materials. Oper. Dent., 2001, 26, 396-400.

11. Kuwata, M., The Theory and Practice for Ceramo-metal Restorations. Quintescence, Chicago, 1980, p. 100.

12. Oliveira, M. C. S., Vieira, A. C., Miranda, C. B. and Noya, M. S., The effect of polishing techniques on the surface roughness of a feldspathic porcelain. Rev. odonto ciênc., 2008, 23, 330-332.

13. Quirynen, M., Bollen, C. M. L., Vanderkerckove, B. N. A., Dekeyser, C., Papaianou, W. and Eyssen, H., Full-versus partial-mouth disinfection in the treatment of periodontal infections: short-term clinical and microbiological observations. J. Periodontol Res., 1995, 74, 1459-1467.

14. Fujisawaa, N., McKenziea, D. R., Jamesb, N. L., Woodardb, J. C. and Swainc, M. V., Combined influences of mechanical properties and surface roughness on the tribological properties of amorphous carbon coatings. Wear, 2006, 260, 62-74.

15. Lohbauera, U., Muller, F. A. and Petschelt, A., Influence of surface roughness on mechanical strength of resin composite versus glass ceramic materials. Dent. Mater., 2008, 24, 250-256.

16. Fleming, G. J. P., El-Lakwah, S. F. A., Harris, J. J. and Marquis, P. M., The influence of interfacial surface roughness on bilayered ceramic specimen performance. Dent. Mater., 2004, 20, 142-149.

17. Fleming, G. J. P., Nolan, L. and Harris, J. J., The in-vitro clinical failure of all-ceramic crowns and the connector area of fixed partial dentures: the influence of interfacial surface roughness. J. Dent., 2005, 33, 405-415.

18. Ahmad, R., Morgano, S. M., Wu, B. M. and Giordano, R. A., An evaluation of the effects of handpiece speed, abrasive characteristics, and polishing load on the flexural strength of polished ceramics. J. Prosthet. Dent., 2005, 94, 421-429.

19. Curtis, A. R., Wright, A. J. and Fleming, G. J. P., The influence of surface modification techniques on the performance of a Y-TZP dental ceramic. $J$. Dent., 2006, 34, 195-206.

20. Aksoy, G., Polat, H., Polat, M. and Coskun, G., Effect of various treatment and glazing (coating) techniques on the roughness and wettability of ceramic dental restorative surfaces. Colloid Surf. B: Biointerf., 2006, 53, 254.

21. Piddock, V., Qualtrough, A. J. and Brough, E., An investigation of an ion strengthening paste for dental porcelains. Int. J. Prostoth., 1991, 4, 132-137.

22. Anusavice, K. J. and Hojjatie, B., Effect of thermal tempering on strength and crack propagation behavior of feldspathic porcelains. J. Dent. Res., 1991, 70, 1009-1013.

23. Anusavice, K. J., Shen, C. and Vermost, B., Strengthening of porcelain by ion exchange subsequent to thermal tempering. Dent. Mater., 1992, 8, 149-152.

24. Oh, W., DeLong, R. and Anusavice, K. J., Effect of connector design on fracture resistance of all-ceramic fixed partial dentures. J. Prosthet. Dent., 2002, 87, 451.

25. Derjaguin, B. V. and Landau, L., Physicochim., URSS, 1941, 14, 633.

26. Verwey, E. J. W. and Overbeek, J. T. G., Theory and Stability of Lyophobic Colloids. Elsevier, Amsterdam, 1948.

27. Höland, W. and Frank, M., Material Science of Empress Glass-Ceramics, in Ivoclar-Vivadent Report (Lichtenstein). No. 10, 1994, p. 3.

28. IPS Empress 2. Instructions for Use Catalogue (Lichtenstein), 2004, p. 29.

29. Polat, H. and Chander, S., Adsorption of PEO/PPO triblock co-polymers and wetting of coal. Colloid Surf. A: Physicochem. Eng. Aspects, 1999, 146, 199.

30. Hiemenz, P. C. and Rajagopalan, R., Principles of Colloid and Surface Chemistry. Marcel Dekker, New York, 1997, p. 252, 464.

31. Polat, M., A review of the theory of interactions between particles dispersed in aqueous media. I. The electrical double layer. J. Ore Dress., 1999, 1, 7-35.

32. Polat, M. and Polat, H., A review of the theory of interactions between particles dispersed in aqueous media. II. Van der Waals interactions. J. Ore Dress., 2000, 2, 21-48.

33. Polat, H. and Polat, M., A review of the theory of interactions between particles dispersed in aqueous media. III. Electrostatic and structural interactions and the DLVO theory. J. Ore Dress., 2000, 2, 1-16.

34. Adamson, A. W., Pysical Chemistry of Surfaces (2nd Edition). Wiley, USA, 1967, p. 358-359.

35. Hogg, R., Healy, T. W. and Fuerstenau, D. W., Mutual coagulation of colloidal dispersions. Trans. Faraday Soc., 1966, 62, 1638-1651.

36. Wolansky, G. and Marmur, A., Apparent contact angles on rough surfaces: the Wenzel equation revisited. Colloids Surf. A: Physicochem. Eng. Aspects, 1999, 156, 381-388.

37. Ponsonnet, L., Reybeier, K., Jaffrezic, N., Comte, V., Lagneau, C., Lissac, M. and Martelet, C., Relationship between surface properties (roughness, wettability) of titanium alloys and cell behaviour. Mater. Sci. Eng. C, 2003, 23, 551-560.

38. Feng, A., McCoy, C., Munir, Z. A. and Cagliostro, D., Wettability of transition metal oxide surfaces. Mater. Sci. Eng. A, 1998, 242, 50-56.

39. Sakar-Deliormanlı, A., Polat, H. and Ciftcioglu, M., Alumina/water suspensions in the presence of PEO-PPO-PEO triblock co-polymers. J. Eur. Ceram. Soc., 2004, 24, 3063-3072. 